\title{
EL FOTOPERIODISMO COMO CAMPO SOCIAL. PROPUESTA PARA EL ESTUDIO DE LA FOTOGRAFÍA PERIODÍSTICA
}

PHOTOJOURNALISM AS A SOCIAL FIELD. PROPOSAL TO STUDY THE JOURNALISTIC PHOTOGRAPHY

Edgar Lara Morales

edgarlaramorales@gmail.com 
Para citar este artículo:

Lara Morales, E. (2021). El fotoperiodismo como campo social: Propuesta para el estudio de la fotografía periodística. ESPACIO I+D, INNOVACIÓN MÁS DESARROLLO, 10(26). https://doi.org/10.31644/IMASD.26.2021.a09

\section{RESUMEN}

La fotografía periodística es un mensaje que se construye, como todo acto comunicativo, para provocar algo y, a través de su articulación con otros elementos, puede llegar a estructurar un discurso complejo que excede en mucho la simple enunciación de un hecho particular.

Además de la propia fotografía, su estudio debe considerar el polo de producción, cuyos intereses y objetivos determinan sus temas, tratamiento y disposición al público. Entender al fotoperiodismo como campo social permite estudiar la relación -en dos sentidos- entre las estructuras objetivas y las estructuras incorporadas en los agentes del campo y su incidencia en la configuración del mensaje.

\section{Palabras clave:}

Fotoperiodismo; fotografía periodística; periodismo. 
$\mathrm{U}$ no de los elementos más importantes del periodismo actual, impreso o digital, es la fotografía. Hoy, a pesar del desarrollo de las tecnologías digitales y de la supuesta crisis general del periodismo, es usada principalmente a manera de prueba fehaciente de hechos o situaciones y se asocia, por su grado de precisión y detalle, a conceptos como verdad y objetividad.

Sin embargo, la fotografía periodística es un mensaje que se construye, como todo acto comunicativo, para provocar algo que, a través de su articulación con otros elementos, puede llegar a estructurar un discurso complejo que excede en mucho la simple enunciación de un hecho particular.

Desde su origen, a consecuencia de la Revolución industrial, a la fotografía se le atribuyó la tarea de documentar, de atestiguar - sin inmiscuirse- los eventos más importantes de la vida familiar, primero, y una vez logrados los ajustes técnicos${ }^{1}$, de la vida pública. De ahí, que la relación fotografíaperiodismo derive de la tradición positivista y se funde en la idea de que los hechos o situaciones de interés público pueden "encapsularse en el tiempo" para ser mostrados a través de la prensa.

En la fotografía el sujeto deviene en objeto y lo irrepetible puede reproducirse al infinito: "hacer una fotografía es participar de la mortalidad, vulnerabilidad, mutabilidad de otra persona o cosa. Precisamente porque seccionan un momento y lo congelan, todas las fotografías atestiguan la despiadada disolución del tiempo" (Sontag, 2006, p.32). El pasado no es más que una reconstrucción exclusiva de la memoria.

\section{LA FOTOGRAFÍA PERIODÍSTICA, UNA CREACIÓN INTELECTUAL}

En el primer cuarto del Siglo XX, la fotografía apareció regularmente en los diarios, sustituyendo de a poco los grabados e ilustraciones que hasta entonces se usaban². Esta nueva "ventana" al mundo, por sus características, revolucionó la forma de hacer periodismo. De acuerdo con Susan Sontag (2003, p.33):

Las fotografías tenían la virtud de unir dos atributos contradictorios. Su crédito de objetividad era inherente. Y sin embargo tenían siempre, necesariamente, un punto de vista. Eran el registro de lo real -incontrovertibles, como no podía llegar a serlo relato verbal alguno pese a su imparcialidad- puesto que una

$1 \quad$ "Para tomar los primeros retratos (hacia 1840) era necesario someter al sujeto a varias poses bajo una cristalería a pleno sol; [...] se inventó entonces un aparato llamado apoyacabezas, especie de prótesis invisible al objetivo que sostenía y mantenía el cuerpo en su pasar a la inmovilidad..." (Barthes, 1990, p.34).

2 Por el tiempo que requería su proceso, las fotografías empezaron a publicarse regularmente en los semanarios como Le Monde Illustré de Francia, el Illustrierte Zeitung de Alemania, y el Illustrated London News de Gran Bretaña. 
máquina estaba registrándola. Y ofrecían testimonio de lo real, puesto que una persona había estado allí para hacerlas.

Ambos atributos señalados por Sontag siguen operando en la fotografía periodística. En un principio, esa objetividad ocupó casi todas las expectativas del fotógrafo, del medio y del propio público, era esa "fuerza probatoria de las imágenes" la que llegó a conferirle un estatus de verdad. De ahí el interés de los gobiernos por distribuir sus propias fotografías.

Hoy sabemos que cuando hablamos de fotoperiodismo necesitamos conceptos menos totalizadores (objetividad / verdad) porque si bien es cierto las fotografías son registro de algo que sucedió, es necesario aclarar que:

Toda fotografía es una ficción que se presenta como verdadera. Contra lo que nos han inculcado, contra los que solemos pensar, la fotografía miente siempre, miente por instinto, miente porque su naturaleza no le permite hacer otra cosa. Pero lo importante no es esa mentira inevitable. Lo importante es cómo la usa el fotógrafo, a qué intención sirve. Lo importante, en suma, es el control ejercido por el fotógrafo para imponer una dirección ética a su mentira. El buen fotógrafo es el que miente bien la verdad (Fontcuberta, 2016, p.17).

Es decir, el fotoperiodista realiza una serie de decisiones para hacer la foto, decisiones que requieren, al menos, entrenamiento, destreza e intencionalidad. Al final, la fotografía es la combinación de la visión del fotógrafo, del uso de una serie de elementos técnicos y compositivos y de las expectativas del medio que las hace públicas. La fotografía periodística es todo, menos objetiva.

En 1924, Ernst Friedich publicó Krieg dem Kriege! (¡Guerra contra la guerra!) un álbum fotográfico sobre los horrores de la Primera Guerra Mundial, secuencias de primeros planos y tomas panorámicas que contravenían abiertamente el discurso de la época a favor de los conflictos bélicos.

A pesar de su amplia aceptación en los círculos intelectuales, sobre todo de izquierda, el gobierno alemán censuró tanto el libro como la exhibición de las fotografías. Los soldados mutilados, los cuerpos pudriéndose, los rostros con heridas casi indescriptibles, se hacían acompañar de pies a cuatro idiomas; juntos diseñaban una especie de clamor para concienciar a la opinión pública y desmentir la propaganda de la guerra.

En Estados Unidos, los trabajos de Friedich, al igual que los de Lewis W. Hine y Jacob Riis ${ }^{3}$ "usaron la cámara como herramienta para mover la

3 Hine hizo fotografías sobre las condiciones en que trabajaban los niños y Riis lo hizo sobre las condiciones de los inmigrantes. Al primero se le atribuye una gran influencia en la Ley Keating-Owen que básicamente reguló el trabajo de menores y al segundo la política social de Roosvelt. 
opinión pública" (Colorado, 2016, p.5). Si bien es cierto estos trabajos no se consideran propiamente fotoperiodísticos, demostraron la capacidad de la imagen fotográfica para tratar fenómenos sociales concretos.

Es pues que, hablar de fotografía es hablar de intencionalidad. Incluso en el ámbito privado, hay una intención que guía el hacer ${ }^{4}$ fotografías: compartir un momento, recodar un evento o situación, mostrarse de cierta manera a los otros, etcétera; cada situación demanda ajustes y decisiones del fotógrafo de acuerdo a sus objetivos, incluso en una selfie.

En el ámbito público, la fotografía periodística materializa una mirada sinecdótica construida desde una posición (política). Una mirada que no es ingenua ni inocua, de intenciones definidas pero camufladas, que en su materialidad desborda la pretensión clásica del periodismo informativo: la objetividad.

De acuerdo a Enrique Villaseñor, en el fotoperiodismo existen cuatro tipos de fotografía: la informativa, la testimonial, el foto-ensayo y la fotoilustración. La informativa prescinde -al menos eso se cree- de la subjetividad del fotógrafo y busca sobre todo la verdad; por su parte, la fotografía testimonial5 se avoca a los fenómenos de tipo estructural y, aquí sí, "se sustenta en la opinión del fotógrafo (...) un periodismo gráfico de opinión que va más allá de la información inmediata” (2011, p.33).

Por otro lado, el foto-ensayo es una narrativa iconográfica sobre algún tema y tal como su nombre lo indica es eminentemente subjetivo, mientras que la foto-ilustración no tiene compromiso alguno con la realidad y se relaciona más bien con intereses de tipo comercial ${ }^{6}$.

Es pues que toda fotografía periodística, fundamentalmente, está comprometida con la realidad y es concebida para llegar al gran público. Ésa es su condición para existir en el ámbito del periodismo y a la vez resulta la mayor de sus limitaciones; el noema de la fotografía según Barthes (1990, p.91): "Esto ha sido $[\neg . .$.$] ha estado allí, y sin embargo ha sido inmediatamente separado;$ ha estado absoluta, irrecusablemente presente, y sin embargo diferido ya".

Reconocer entonces que más allá de nuestras pretensiones, la fotografía -a secas- no es la realidad en sí misma o su análogo y, en consecuencia, la fotografía periodística tampoco, implica además repensar el papel del fotógrafo.

4 Hacer en lugar de tomar fotografías. Hacer reconoce implícitamente la acción del fotógrafo; tomar, en cambio, le reserva un lugar marginal. En lo primero se reconoce que la fotografía es construcción, en lo segundo, sólo reproducción.

5 Tradicionalmente llamada "documental".

6 Villaseñor incluye este tipo de fotografía recurriendo a la clasificación de Pepe Baeza en Por una función crítica de la fotografía de prensa (2007). Sin embargo, la foto-ilustración no cabe en este ensayo puesto que no trata necesariamente de hechos de interés público, ni tiene relación estrecha con el ámbito noticioso o informativo. Habría que hacer una distinción entre fotografía de prensa; es decir, aquella que aparece regularmente en la prensa, y fotografía periodística que, como se dijo, está vinculada forzosamente a hechos de interés público. 
Es decir, la fotografía periodística no es más el trabajo mecánico de reproducir la realidad, sino una creación intelectual -de un sujeto- que tiene como materia prima hechos de interés público, que se constituye como medio y mensaje ${ }^{7}$ para distribuirse a través de distintos soportes y modalidades.

Siguiendo a Gamarnik (2010, p.17) "la fotografía muestra una gran ductilidad y la posibilidad de ser usada en instancias múltiples” y su sentido - cambiante e histórico-depende de los usos sociales; por lo tanto, al superar el mito de la objetividad que se usó casi indiscriminadamente desde su invención, el estudio de la fotografía, incluyendo la de tipo periodístico, debe avocarse a la producción; es decir, al polo creador, cuyos intereses y objetivos determinan la configuración del mensaje.

En su distopía 1984, George Orwell (1948) plantea el interés del gobierno, del Ministerio de la verdad, por controlar el pasado a través de sus documentos y registros para así justificar sus acciones en el presente. Si la fotografía periodística contribuye a registrar eventos o situaciones de interés público que el tiempo convierte en documentos, entonces ¿̇cómo interviene ésta en la construcción de la historia?

La Alemania Nazi, por ejemplo, tuvo en las fotografías de Hugo Jaeger, un fotógrafo personal de Hitler, el artilugio perfecto para registrar todo el sistema de propaganda del Tercer Reich. No eran únicamente la suástica, o el uso predominante del rojo, blanco y negro, sino también las impecables formaciones de los soldados, la precisa colocación de las banderas, y en general, la disposición de los elementos distintivos de cualquier concentración oficial Nazi. De acuerdo con Ben Cosgrove (2014), todos estos elementos - registrados por Jaeger- contribuyeron a la construcción del mito de Hitler, Goebbels, Himmler y Goering, y sobre todo, a percibir al nazismo, al menos por algunos años, como imparable.

En Argentina, durante el primer gobierno peronista, se creó la Subsecretaría de Informaciones de la Presidencia de la Nación, que se encargó de producir y distribuir propaganda gubernamental y, a su vez, una división fotográfica dedicada casi exclusivamente a construir la imagen de Perón y -posteriormente $\neg-$ de Eva Perón. En esa área se crearían "la fotografía más repetida y difundida entonces de la iconografía peronista" -Perón a caballo-, y aquella de Evita "elegida por la juventud peronista durante la década del 70 como símbolo propio” (Gamarnik, 2010, p.5).

En contraposición, en 1981 un grupo de fotógrafos llevó a cabo la primera muestra del Periodismo Gráfico Argentino “con el objetivo de exponer las

7 En el mismo documento, Villaseñor explica que la fotografía periodística es a la vez medio y mensaje porque funciona como vehículo para transmitir otros mensajes a través de distintos soportes (2011, p.30). 
fotos que habían sacado durante esos años [durante los gobiernos de Perón] y que no habían sido publicadas o habían sido directamente censuradas por los grandes medios" (p.13).

En México, el movimiento estudiantil del 68 y su terrible desenlace -hace ya más de 50 años- significó un sisma en lo más hondo del sistema político mexicano, incluyendo por supuesto, el ámbito periodístico. Los mensajes desde el gobierno se hicieron acompañar de censura a las voces contestatarias; se instauró un dispositivo de control de la información que cuartó por igual el ejercicio periodístico de medios, reporteros y fotoperiodistas ${ }^{8}$.

Afortunadamente muchos archivos fotográficos se conservaron y con el paso del tiempo han visto la luz. Es el caso de los portafolios de Armando Lenin y Manuel Gutiérrez "El Marichito" -fotógrafo de la Secretaría de Gobernación-, que la revista Cuartoscuro presentó en 2008; dos miradas del mismo movimiento, una construida desde el ámbito periodístico y otra desde el poder.

\section{ABORDAJES A LA FOTOGRAFÍA PERIODÍSTICA}

Aún hoy, la fotografía periodística no ocupa un lugar prominente dentro de los estudios sobre periodismo. En México, por ejemplo, los trabajos de investigación se enfocan principalmente en los textos escritos, confiriendo una posición accesoria a la fotografía de este tipo. Es cierto que muchos medios locales y nacionales privilegian el uso de la fotografía a manera de ilustración, esto es, desvinculada completamente de la pieza periodística de junto; sin embargo, el solo incremento en los últimos años del número de imágenes fotográficas publicadas en los diarios, tanto impresos como digitales, justifica la necesidad de abordarla a través de estudios rigurosos que la conciban como protagonista en el ámbito.

Ahora bien, existen varias formas de estudiar a la fotografía. Siguiendo el esquema de Laswell, Javier Marzal expone que cada instancia conlleva una forma de aproximarse al objeto de estudio. Están los trabajos de corte biográfico y los de tipo histórico; también los hay tecnologista y los que parten de orientaciones iconológicas o semióticas; por supuesto, cada uno de ellos tiene implicaciones y limitaciones. Sin embargo, se trata de un campo en desarrollo.

El propio Javier Marzal (2011, p.12) explica que los estudios sobre la imagen fotográfica normalmente "se ha[n] desarrollado en el marco del

8 Confiscar rollos fotográficos en mítines fue una tarea recurrente de los agentes de Gobernación, militares y paramilitares de la época. 
mundo del coleccionismo y de la crítica fotográfica en revistas especializadas y de divulgación". Es decir, a pesar de su masificación en la segunda mitad del Siglo XX, la fotografía se ha estudiado, sobretodo, desde los círculos intelectuales y artísticos.

Walter Benjamin (1973), por ejemplo, uno de los pensadores de la Escuela de Frankfurt, estudió a la fotografía como una subversión del concepto de arte. Debido a su capacidad de reproducción, la fotografía trastoca sus límites de autenticidad y originalidad del arte hasta convertirlo en mercancía.

Por su parte, la fotógrafa y socióloga Gisèle Freund (1974), a través de la oposición histórica pintura/fotografía, introduce la idea de que los cambios en la estructura social influyen lo mismo en los temas como en las modalidades de la expresión artística. Es decir, desde su perspectiva, hay una incidencia innegable de la estructura sobre lo que se considera arte.

Ahora bien, Joan Fontcuberta (2016), Jacob Bañuelos (2014), Pepe Baeza (2001), entre otros, han desarrollado trabajos sobre los límites, implicaciones y transformaciones de la fotografía en su uso como herramienta periodística; esto, claro, de acuerdo a las estructuras del ámbito periodístico, sin negar los atributos inherentes a la propia fotografía.

Tal como sostiene Roland Barthes (1986, p.15), más allá de su concepción como documento análogo de hechos y situaciones, "la fotografía de prensa es un objeto trabajado, escogido, compuesto, elaborado, tratado de acuerdo con unas normas profesionales, estéticas e ideológicas que constituyen otros tantos factores de connotación".

Por ejemplo, en Chiapas, en el conflicto de 1994 entre el Ejército Zapatista de Liberación Nacional (EZLN) y el gobierno federal, que inicialmente fuera armado y que derivara en una estrategia informacional ${ }^{9}$, la fotografía de prensa fue determinante. De acuerdo con Flor Gómez (2015, p.245), la guerrilla configuró un espacio de representación que incluyó el disfraz, las localizaciones simbólicas y un estilo épico que se distribuyó a través de la fotografía de prensa.

Las fotografías publicadas en la prensa sobre los hechos de Chiapas ofrecen información ideológica, sirviendo a la propaganda de la guerrilla Ejército Zapatista de Liberación Nacional. Nos lleva a esta afirmación la detección de ciertos elementos en las imágenes que, relacionados, fijan ideas, conceptos, símbolos, en definitiva, propagandemas.

Para Gómez Cortecero el material gráfico publicado en España sobre el conflicto armado de Chiapas, por un lado comprueba que "la fotografía de

Manuel Castells (2009) considera al EZLN como la primera guerrilla informacional -del mundo-. 
prensa es, efectivamente, un medio capaz de establecer unas estrategias de persuasión y de crear opinión”, y por otro que, al menos en este caso, sirvió para ofrecer información ideológica de acuerdo con los intereses propagandísticos de EZLN (2015, p.242). Este trabajo de investigación, entonces, encontró una intencionalidad subyacente que condicionó la forma de hacer fotoperiodismo sobre la guerrilla. Una situación sui generis que evidencia la necesidad de entender a la fotografía periodística como un mensaje dentro de una estructura que, se materializa a través del ejercicio del fotógrafo.

Si se atiende esta exigencia, entonces, puede observarse que el fotoperiodismo forma parte de una estructura informacional mayor, con intereses mercantiles, pero, sobre todo, políticos; que se sirve de la naturaleza de la fotografía, de cómo se percibe ésta en lo cotidiano, para construir un discurso de gran peso semántico.

Desde esta posición se abre la puerta para estudiar no sólo a la fotografía de los gobiernos o de las distintas entidades políticas, sino a la propia fotografía periodística como instrumento de propaganda política. La fotografía periodística no es más la realidad, ni la reproducción del referente, sino un mensaje que se construye deliberadamente.

Desde los Estudios Culturales, Osiris Aquino (2018) plantea que existe un sesgo de género en el trabajo de los fotoperiodistas varones, a consecuencia de la estructura heteropatriarcal normalizada que configura su forma de ver. Desde este punto de vista, la mirada se construye a través de la cultura e inevitablemente reproduce sus formas estereotipadas.

De tal modo que, sin ser conscientes de ello, a través de su trabajo, los fotoperiodistas no solo invisibilizan a ciertos grupos sociales (mujeres e integrantes de LGBTTTIQ ${ }^{10}$ ), sino que además construyen sus mensajes a partir de una carga negativa en consonancia con el discurso dictado desde la hegemonía masculina.

Es decir, para este trabajo los mandatos estructurales se interiorizan a través de la cultura para luego ser reproducidos a través de la fotografía periodística, en tanto extensión de la mirada de los sujetos. El componente político entonces se complejiza a través de un nuevo elemento: la cultura.

Cabe preguntarse, entonces, ¿cómo puede estudiarse la fotografía periodística sin caer en visiones reduccionistas, es decir, reconociéndola como mensaje estructurado en que se materializan tanto la intencionalidad del fotógrafo como los elementos estructurales del ámbito periodístico? 


\section{POLÍTICA Y CULTURA, ESPACIO DE PRODUCCIÓN DE LA FOTOGRAFÍA PERIODÍSTICA}

La fotografía periodística interesa en tanto documento que cristaliza, explícita o implícitamente, por un lado, los objetivos e intereses del mercado de la información, y a su vez, las subjetividades del fotógrafo. De tal forma que para entenderla resulten indisociables los unos de las otras.

Los Estudios Culturales, en su vertiente latinoamericana, que surge a mediados del siglo pasado, se enfocan principalmente en "los espacios de resistencia entre la cultura popular y de masas" (Szurmuk y Mkee, 2009, p.9). Este campo interdisciplinario "hereda de la diáspora intelectual judeoalemana exiliada del nazismo, la preocupación por el poder de la industria cultural y el interés por analizar nuevos modos de producción cultural, muchas veces con el signo cambiado" (Szurmuk y Mkee, 2009, p.12).

Es decir, los Estudios Culturales, entre otras cosas, reformulan las preocupaciones de la Escuela de Frankfurt, que planteaban una sociedad masificada sin libertad individual, para dar paso, a consecuencia principalmente del posestructuralismo, a una sociedad con capacidad de producir sentido (Szurmuk y Mkee, 2009, p.13).

En este contexto, las teorías de las mediaciones ${ }^{11}$, sobre todo la desarrollada por Jesús Martín Barbero en De los medios a las mediaciones: comunicación, cultura y hegemonía (1991) han resultado en toda una escuela de reflexión sobre los medios masivos y la globalización en Latinoamérica.

En esta obra, Martín Barbero plantea que la comunicación es más una cuestión de cultura que de medios, que la idea de emisores-dominantes y receptores-dominados era insuficiente para explicar lo que sucedía en un escenario de "memorias e imaginarios que revuelven lo indígena con lo rural, lo rural con lo urbano, el folklore con lo popular y lo popular con lo masivo" (Barbero, 1991, p.10).

Martín Barbero plantea una especie de conversión; formular las preguntas no desde los lugares comunes de la tradición académica, sino desde su opuesto; esto significa "re-ver el proceso entero de la comunicación desde su otro lado, el de la recepción, el de las resistencias que ahí tienen su lugar, el de la apropiación desde los usos" (1991, p.10).

Sin embargo, a consecuencia del desplazamiento teórico que ubicó a la cultura en el centro de interés, los estudios sobre comunicación latinoamericana, sobre todo los que derivan de las teorías de las mediaciones, han evidenciado un "marcado proceso de despolitización":

11 En 1977, Manuel Martín Serrano publicó La mediación social. 
El estudio segmentado, descontextualizado y a escala micro del proceso de recepción; la indiferencia hacia los vínculos de los medios con la ideología, la dependencia y el poder; así como la adopción de agendas de investigación diseñadas desde el mercado empresarial, son algunas de las manifestaciones de esta pérdida del sentido crítico y utópico de la investigación (Gámez, 2007, p.207).

Es decir, si bien es cierto, los trabajos sobre las mediaciones evidenciaron la insuficiencia de las categorías analíticas para dar cuenta del proceso de comunicación masiva, éstos se centraron principalmente en la relación sujeto-prácticas culturales, dejando de lado las categorías políticas de poder o por decirlo de otra manera, las categorías que se refieren a las grandes estructuras (Gámez, 2007, p.208).

La fotografía periodística, como se mencionó líneas arriba, se ocupa de los asuntos de interés público, noticiosos o no. Su área de acción es amplia y compleja porque se relaciona con las dinámicas sociales; en consecuencia, encaja perfectamente en las lógicas de los medios masivos cuyo interés primordial es la difusión de contenidos a gran escala.

Aunque existen ejemplos de fotografía periodística con el estatus de arte, ésta no pretende, en primera instancia, encerrarse en una especie de solipsismo intelectualoide; por el contrario, su principal objetivo es su distribución masiva, alcanzar al gran público. Si se hiciera una analogía con la pintura -una más- la fotografía periodística sería un mural frente a la pintura de caballete.

De acuerdo a García Canclini (2000, p.72) la recomposición de lo público dentro de los países y el cuestionamiento de las formas clásicas de representatividad han problematizado las distintas concepciones de esfera pública:

lo público se desarrolla tanto en los diarios y la radiodifusión como en los entretenimientos, no sólo en los medios bajo control estatal o concebidos como servicio público sino también en los talk shows televisivos, los videojuegos, los concursos en que se premian éxitos personales y habilidades como si fueran desempeños públicos (García, 2000, p.75).

En ese sentido, en la medida en que se distribuye, la fotografía periodística participa de esa escena deliberativa que desborda los mecanismos clásicos de representatividad, de ese espacio simbólico complejizado por las industrias

12 El mexicano Enrique Metinides, fotógrafo de nota roja, ha expuesto su trabajo en museos como el Recontre d'Arles Photographie de Francia, el Aperture Gallery de Nueva York, y el Fair Royal College de Inglaterra. 
de la comunicación e información, donde se discuten los asuntos públicos, donde se hace política.

Por lo tanto, es indispensable atender el componente político inmanente en todo acto comunicativo que tiene lugar en los media, sin obviar el contexto cultural de que es parte; ambos, política y cultura, son los marcos de interpretación de los contenidos de los medios; ambos son, también, el espacio de producción de la fotografía periodística.

Resulta imperativo entonces, además de analizar a la propia fotografía periodística como un mensaje complejo y estructurado, dar cuenta de las motivaciones e intencionalidades del polo productor; es decir, del fotógrafo: un sujeto que crea pero que a la vez reproduce, que se debe a la sociedad pero que depende de una industria, que ve pero sobre todo, mira.

\section{DE LA FOTOGRAFÍA PERIODÍSTICA AL FOTOPERIODISMO Y VICEVERSA}

Entender a la fotografía periodística como un texto en contexto, que además es estructurada deliberadamente, demanda reflexionar sobre el papel que desempeña el fotoperiodista como ente político; es decir, como parte del entramado de relaciones no sólo de la industria periodística, sino también del ámbito económico y social; y, por si fuera poco, como sujeto -que no está determinado por la estructura- con capacidad de agencia.

Lo anterior conlleva entender que la fotografía periodística está construida en el seno de un campo social ${ }^{13}$, en la acepción de Pierre Bourdieu (1997), en un entramado de relaciones y estructuras que determinan lo que se entiende como legítimo y lo que no lo es, y que indefectiblemente inciden en su ejercicio diario. Este campo es el fotoperiodismo.

Pensar al fotoperiodismo como campo nos apremia a estudiar la relación -en dos sentidos- entre las estructuras objetivas y las estructuras incorporadas $^{14}$, es decir, entre los otros campos sociales y los habitus; los primeros como estructuras exógenas y los segundos como prácticas interiorizadas.

13 En Razones prácticas. Sobre la teoría de la acción (1997, p.49), respecto del espacio social, el autor explica que un campo es "un campo de fuerzas, cuya necesidad se impone a los agentes que se han adentrado en él, y como un campo de luchas dentro del cual los agentes se enfrentan, con medios y fines diferenciados según su posición en la estructura del campo de fuerzas, contribuyendo de este modo a conservar o a transformar su estructura".

14 En la década del 60, Pierre Bourdieu realizó un estudio sobre la función social de la fotografía en Francia. El trabajo se centraba en el sentido de la práctica fotográfica, específicamente de las clases populares. El documento da cuenta de que la fotografía, más que una actividad espontánea, parte de la realidad en la que existe y materializa además de las intenciones del sujeto, los sistemas de pensamiento de todo un grupo. 
En otras palabras, con fotoperiodismo hablamos de agentes e instituciones y de sus prácticas y relaciones en un contexto específico; esto es, fotógrafos, editores y empresas periodísticas (de productos impresos o digitales), principalmente, y su incidencia en la configuración de la fotografía periodística.

La demanda aquí es entender que la fotografía periodística no puede estudiarse sin atender al polo de producción (incluyendo al propio fotógrafo), cuyas lógicas determinan sus temas, su tratamiento y su disposición al público; es decir, los márgenes en que ésta se desenvuelve.

Estudiar lo fotografía periodística por sí sola o como una reproducción de la realidad, evidencia un serio problema de relación entre el investigador y su objeto de estudio porque excluye, en una ecuación simplista, el componente político, que es en esencia lo que motiva al fotoperiodismo. 


\section{REFERENCIAS}

Aquino, P. (2018). La construcción de la mirada de la y el fotoperiodista en Chiapas: la ginopia en los hechos noticiosos. (Tesis de maestría) Universidad Autónoma de Chiapas.

Baeza, P. (2007). Por una función crítica de la fotografía de prensa. España: Gustavo Gili.

Barthes, R. (1986). Lo obvio y lo obtuso. Imágenes, gestos y voces. España: Ediciones Paidós.

Barthes, R. (1990). La cámara lúcida. Nota sobre la fotografía. España: Ediciones Paidós.

Bourdieu, P. (1997). Razones prácticas. Sobre la teoría de la acción. Barcelona: Anagrama.

Castells, M. (2009). Comunicación y poder. Alianza: Madrid.

Colorado, O. (2016). Los inicios del fotoperiodismo 1900-1930. Oscarenfotos.com. https://oscarenfotos.files.wordpress.com/2016/07/inicios_fotoperiodismo_ pdf_hd.pdf

Cosgrove, B. (2014). A Brutal Pageantry: The Third Reich's Myth-Making Machinery, in Color. Time. http://time.com/3490218/a-brutal-pageantry -the-third-reichs-myth-making-machinery-in-color/

Fontcuberta, J. (2016). El beso de judas. España: Gustavo Gili.

Gamarnik. C. (2010). La fotografía como instrumento político en Argentina: análisis de tres momentos clave. Academia.edu. https://www.academia.edu/5602884/ La_fotograf\%C3\%ADa_como_instrumento_pol\%C3\%ADtico_en_Argentina _análisis_de_tres_momentos_clave

Gámez, N. (2007). El paradigma de la mediación: crítica y perspectivas. Mediaciones sociales. 1. 195-213.

García Canclini, N. (2000). Políticas culturales: de las identidades nacionales al espacio latinoamericano en Las industrias culturales en la integración latinoamericana. (pp.67-84) México: Grijalbo.

Gómez, F. (2015). Propaganda e imagen: El conflicto de Chiapas en la prensa española. (Tesis de doctorado) Universidad de Málaga. https://riuma. uma.es/xmlui/handle/10630/10352?show=full

Martín-Barbero, J. (1991). De los medios a las mediaciones. Comunicación, cultura y hegemonía. México: Gustavo Gili.

Marzal, J. (2011). Aproximaciones metodológicas en el estudio de la fotografía. Research Gate. https://www.researchgate.net/publication/47936503_ Aproximaciones_metodologicas_en_el_estudio_de_la_fotografia

Orwell, G (2002). 1984. México: Lectorum.

Sontag, S. (2006). Sobre la fotografía. México: Alfaguara.

Sontag, S. (2003). Ante el dolor de los demás. Daruma. 
Szurmuk, M. y Mkee, R. (2009). Diccionario de Estudios Culturales Latinoamericanos. México, D.F.: Siglo XXI Editores.

Villaseñor, E. (2011). Algunas reflexiones en torno a géneros fotográficos. Fotoperiodismo.org http://www.fotoperiodismo.org/fotografiadocumental.pdf 